\title{
¿La clase social entre paréntesis? El caso de la Aldea Gay en Buenos Aires
}

\author{
María Carman \\ Universidad de Buenos Aires (UBA)
}

\section{¿La clase social entre paréntesis? El caso de la Aldea Gay en Buenos Aires}

Resumen: En este artículo se tomará como eje de reflexión el caso de la Aldea Gay, una villa de Buenos Aires desalojada por el gobierno local para la construcción de un nuevo corredor de parques. El interés de este trabajo consiste en abordar de qué modo estos sectores populares son construidos como destinatarios cuasi naturales de la violencia estatal, haciendo hincapié en los cruces entre género y clase social. En segundo lugar, se señalará el modo en que los habitantes de la aldea desafían los mecanismos de dominación reelaborando los elementos en nombre de los cuales se ejercen violencias sobre ellos: el medio ambiente, la clase social y su condición gays/travestis. El supuesto es que la cuestión de clase es desplazada, en los sectores populares estudiados, cuando esta no resulta provechosa como elemento reivindicativo per se.

Palabras clave: ciudad de Buenos Aires, género, medio ambiente, clase social.

\section{A classe social entre parêntesis? O caso da Aldeia Gay em Buenos Aires}

Resumo: Este artigo toma como eixo de reflexão o caso da Aldeia Gay, uma favela de Buenos Aires, desocupada pelo governo local para a construção de um novo corredor de parques. O interesse deste trabalho consiste em abordar de que maneira estes setores populares são construídos como destinatários quase naturais da violência estatal, com base nas intersecções de gênero e classe social. Em segundo lugar, mostrar-se-á a forma como os habitantes da favela desafiam os mecanismos de dominação, reelaborando os elementos em nome dos quais se exercem violências sobre eles: o meio ambiente, a classe social e sua condição de gays/travestis. Acredita-se que a questão de classe é ignorada, nos setores populares estudados, quando não é proveitosa como elemento reivindicativo per se.

Palavras-chave: cidade de Buenos Aires, gênero, meio ambiente, classe social.

\section{Social Class in Parenthesis: the Case of the Aldea Gay Neighborhood in Buenos Aires}

Abstract: This article focuses on the case of the Aldea Gay, a neighborhood in Buenos Aires which was demolished by the local government to build a corridor of parks. It focuses on how these popular sectors are constructed as nearly natural recipients of state violence, based on intersections of gender and social class. Secondly, the study shows how the residents of the neighborhood challenged the mechanisms of domination, re-elaborating the elements in the name of which they are the subjects of violence: the environment, social class and their condition as gays and transvestites. It is understood that the question of class is ignored in the popular sectors studied, when it is not advantageous to raise it as a factor per se.

Key words: city of Buenos Aires, gender, environment, social class. 


\section{Introducción}

En este artículo tomaré como eje de reflexión el caso de una villa de Buenos Aires desalojada por el gobierno local para la construcción de un nuevo corredor de parques frente al Río de la Plata. Se trata de un sitio casi invisible de la ciudad de Buenos Aires: la Aldea Gay, oculta en la franja costera de Ciudad Universitaria. Asentada sobre terrenos ganados al río en el coqueto barrio de Núñez, la Aldea Gay debe su nombre a la comunidad que fundó allí un grupo de cartoneros gay que vivía en la calle. Estos habitantes cargan con una trayectoria de complejos vínculos con agencias estatales locales, que incluye sistemáticas violaciones a sus derechos humanos: abusos sexuales, violaciones, quema y robos de pertenencias.

A esta primera población se suman, con el correr de los años, familias provenientes de otras villas, hasta completar un total de 95 familias. Luego de que sus pobladores sufrieran un abandono estatal casi absoluto, la villa fue desalojada definitivamente en 2006. El argumento central que justificó dicha expulsión fue la necesidad de culminar el Parque Natural y del Parque de la Memoria que se estaban construyendo sobre ese predio, para honrar la memoria de los desaparecidos de la última dictadura militar.

En particular, he de analizar aquí dos cuestiones. En primer lugar, abordaré de qué modo estos sectores populares son construidos como destinatarios cuasi naturales de la violencia estatal, haciendo hincapié en los cruces entre género y clase social. Si clase y género dividen y clasifican el mundo de distintas maneras, es necesario analizar, en cada formación social específica, de qué modo se articulan entre sí para establecer posiciones sociales (HALL, 1985, p.111). Veremos cómo la condición sexual de los habitantes de la aldea era percibida por otros actores como una carencia que, sumada a su clase social y precario estatus laboral, justificaba la exclusión.

En segundo lugar, quiero señalar brevemente el modo en que los habitantes de la aldea desafían los mecanismos de dominación reelaborando los elementos en nombre de los cuales se ejercen violencias sobre ellos: el medio ambiente, la clase social y su condición gay/ travesti. Mi supuesto es que la cuestión de clase es desplazada, en los sectores populares estudiados, cuando esta no resulta provechosa como elemento reivindicativo per se $e^{1}$. A la circunstancia de no ser sino pobre o villero, los habitantes de la Aldea Gay le adicionan un plusvalor cultural, unido a la reivindicación del entorno natural y de su condición sexual.

\section{Metodología utilizada}

Para esta investigación opté por una estrategia metodológica cualitativa, de corte etnográfico. Esto supone la indagación de las representaciones y las prácticas de los diferentes actores sociales involucrados y compromete la integración de ciertas herramientas técnicas con las dimensiones de lo local, como la utilización de entrevistas abiertas o semidirigidas, y las observaciones con y sin participación. Los objetivos apuntaron a estudiar la tensión entre naturaleza, cultura y segregación socioespacial en un espacio urbano público en disputa de la ciudad de Buenos Aires, enfatizando tanto en las transformaciones urbano-culturales implicadas, como en las luchas materiales y simbólicas por formas de reconocimiento social desplegadas por los distintos actores sociales implicados.

La unidad de estudio escogida está conformada por escenarios delimitados en la Costanera Norte de la ciudad de Buenos Aires (la ex Aldea Gay, y actual Parque Natural en construcción); ya que surgen como espacios apropiados en donde indagar las cuestiones de esta temática, a través de un análisis tanto diacrónico como sincrónico que tenga en cuenta sus aconteceres históricos. El universo de análisis apuntó a contemplar a todos los actores sociales relevantes en el marco de los objetivos propuestos: habitantes de la Aldea Gay; agrupaciones ambientalistas y de derechos humanos; integrantes de instituciones locales; empleados $\mathrm{y}$ funcionarios de diversas delegaciones del poder local; distintos actores vinculados a Ciudad Universitaria, etc. Amén de innumerables fuentes secundarias, el trabajo se apoyó en observaciones y entrevistas con diverso grado de estructuración a los actores mencionados. Al interior de la villa, entrevisté a habitantes de distintas edades -hombres, mujeres, gays, travestis- que aportaron una valiosa perspectiva sobre el derrotero de sus existencias.

Asimismo, el proyecto fue sometido al Comité de Ética en Investigaciones con Seres Humanos tanto de la Universidad de Buenos Aires como del Consejo Nacional de Investigaciones Científicas y Técnicas, del cual soy Investigadora adjunta; ambos con parecer favorable. Fue solicitado el consentimiento libre y esclarecido de los sujetos entrevistados, a partir de un término de consentimiento para esta publicación, debidamente consensuado entre el actor entrevistado y el investigador. Se ha asegurado la confidencialidad y privacidad de sus testimonios, garantizando la no utilización de informaciones en perjuicio de los que participaron de la investigación, y observándose las normas legales y éticas para las pesquisas que involucran seres humanos.

A continuación voy a presentar los relatos del tiempo primordial de la aldea desde el punto de vista de sus habitantes. Estas versiones de los orígenes de la aldea, reactualizadas periódicamente, intervinieron en la disputa por su permanencia en la ciudad incluso hasta el momento del desalojo. 


\section{Debajo del paraíso}

La Pedro tiene 52 años, es uruguayo y está en pareja con el Pedro desde hace una década. Luego de vivir en Uruguay y Brasil, decide probar suerte en Buenos Aires. Llegar a la ciudad fue conocer, al poco tiempo, un circuito de compañeros gays sin techo, y un nuevo oficio: el cirujeo. En el medio hubo trabajos en metalúrgicas, en cosechas de provincias, como operarios de limpieza en shoppings y dependencias públicas. Esporádicamente se alojaban en hotelespensión, hasta que en grupo decidieron largar todo y dedicarse a cirujear.

En el carrito 57 de la Costanera nos juntábamos todos los gays. Tomábamos el tren a Retiro y de ahí al obelisco. [...] Estábamos todos en la calle. Dormíamos en el subte. [...] Para esa época [monseñor] Quarracino salió a decir dijo que los putos ${ }^{2}$ deberían vivir todos juntos en una isla. $\mathrm{Y}$ en eso vino Caty y nos dijo: 'Che viste que Quarracino dijo que los putos tienen que vivir en una isla? Yo tengo el lugar!' Era todo monte. 'Y qué hacemos', dijimos. 'Vamos a hacer un rancho...' [ ....]Yo dormía debajo del paraíso (se ríe, acentuando la doble acepción del árbol y de edén). [...] Mi techo era de bolsas de consorcio... Ahí fue nuestra primer ranchada (La Pedro).

El mito de la instalación territorial del grupo muestra la historia de un nuevo comienzo: el armado de un mundo propio en una ciudad que los rechaza. En ese otro tiempo-"el gran tiempo" - que evoca la fundación mítica de la aldea, se salvaguarda el principio moral de domesticar ese espacio inexpugnable, como un triunfo de la perseverancia y el trabajo. La actividad creadora "in illo témpore" - el desmalezamiento, el desmonte, la intimidad con el río - evoca una celebración mítica de la naturaleza (RIVIÉRE, 2001, p. 33), así como la función redentora de la dificultad ${ }^{3}$. La visión del paraíso también es reivindicada por los demás "fundadores" que sobrevivieron:

Era la sede. La Aldea Gay. Todo rancho así, el centro alfombrado, un mástil y una bandera; era hermoso. Cuando peleábamos, trincábamos ${ }^{4}$... [...] Esa fue una época inolvidable...y la mayoría murieron todos (Nicolás).

La bandera a la que refiere Nicolás (aproximadamente 45 años) es la bandera del Arco Iris o bandera del Orgullo Gay, símbolo de la diversidad - y al mismo tiempo de la unidad - de la comunidad gay.

Para llegar a la aldea es necesario ingresar en la Ciudad Universitaria de Buenos Aires, un campus ubicado en el último extremo de la Costanera Norte. Detrás del segundo pabellón nace un sendero por el cual se accede a una península de 5 hectáreas circundada por el Río de la Plata. Entre la frondosa vegetación - y bajo los rugidos constantes del cercano Aeroparque -, se vislumbran los ranchos sin luz ni agua, construidos a base de madera, plástico y otros materiales.

La circunstancia de vivir sobre el margen del río, alejados del centro urbano y de toda mirada, facilitó la completa impunidad con que las fuerzas policiales acometieron contra su población original: abusos físicos, psicológicos, robos de pertenencias, allanamientos, quema de ranchos, el pago de porcentajes de ganancias a quienes ejercían la prostitución, y demoras en la comisaría por estar vestidos de mujer. La impunidad también fue alimentada por la percepción que se tenía de ellos: no eran sino usurpadores gays/travestis - aun cuando se tratara de travestis "jubilados" - anclados a una esfera privada, casi secreta y de extrema pobreza. El simple hecho de "estar ahî" y, en apariencia, sin derechos, habilitaba el ejercicio de la violencia institucional. Por otra parte, puesto que los gays/ travestis eran sujetos de una práctica sexual considerada objetable, también podían ser objeto pasivo de la satisfacción sexual de los policías ${ }^{5}$.

Yo tuve que acostarme con un milico 6 uniformado para que no me lleve preso [... ] Mi cabeza no valía nada (La Pedro).

La clandestinidad de la usurpación era vivida por sus habitantes como un impedimento para denunciar lo ilícito de estas prácticas. Los policías les advertían además que por el solo hecho de estar viviendo ahí no tenían derecho a reclamos; como si los "aldeanos" tuvieran, en su "aislamiento ilegal", una suerte de estatus prepolítico que justificara los abusos ${ }^{7}$.

Los habitantes reivindicaron la aldea como un espacio de libertad, pese a que el ejercicio de la libertad se vio continuamente obstruido por la violencia policial. Un día feriado de 1998, bajo la lluvia, ellos sufrieron un violento desalojo: los ranchos fueron quemados, sus animales muertos y sus pertenencias, robadas. Una habitante travesti permaneció viviendo oculta entre los pastizales, pese a la constante vigilancia policial; y el resto de los pobladores se trasladó debajo del puente de una cercana e inhóspita estación ferroviaria. Durante aquel mes a la intemperie, en pleno invierno, tres de ellos - portadores de HIV -, murieron ahí mismo o en el hospital.

La ubicuidad de la muerte otorga un espesor peculiar al mito fundacional de la aldea: se alude a los amigos muertos en el puente, a los que continúan internados con HIV, al extraño cadáver que apareció un día, a los cuerpos enterrados clandestinamente. El fin de la vida completa aquí, a mi parecer, el gran tema mítico del comienzo de las cosas, y carga con el mismo carácter dramático o solemne, emocional y ejemplar. 


\section{La llegada de las familias}

La aldea cambia de estatus cuando llegan otros habitantes a partir de la crisis socioeconómica de fines de 2001. Los “fundadores" admiten que la llegada de familias les confiere mayor reconocimiento y protección: logran en forma conjunta asistencia alimentaria, visitas del Centro de Salud, ayuda de Ciudad Universitaria, y el armado de una huerta.

Hasta el 2001 éramos todos solos. [...] Peleábamos por la gente de la calle solos [...] Antes no nos conocían ni los perros... [...] Para mí es como una bandera flameando: es un triunfo. Antes no éramos nada... (Nicolás).

Los habitantes gays buscan transformarse en interlocutores legítimos del Estado a través de distintas vías: ya sea mediante la incorporación de las familias a los reclamos, o apelando a las organizaciones que les brindan ayuda por su condición gay. Desde el punto de vista de la comunidad originaria gay/travesti, el "nosotros" de la aldea es fluctuante: puede incluir a las noventa familias (incluyendo a ellos, los "solteros") o bien solamente a los "nativos". Frente a ciertas circunstancias o interlocutores, conviene achicar o ensanchar el grupo de pertenencia.

Ellos se perciben como portadores de una cultura original o diferenciada, en buena medida, a partir del reconocimiento que les confieren disímiles actores de la sociedad civil en su vínculo intersubjetivo. Lo interesante es que, aun en los casos en que dichos vínculos se vieron posteriormente interrumpidos o deteriorados, persistieron los efectos simbólicos de tales encuentros, que pueden resumirse en una confianza interiorizada9. Para los habitantes de la aldea, no solo aparecen nuevos modos de pensarse a sí mismos, sino de presentarse y representarse en tanto grupo. En los sucesivos contactos con ONGs, se busca no solo satisfacer demandas sino también gestionar, lo más exitosamente posible, el capital simbólico del grupo. En efecto, el apoyo de dichas instituciones será comentado y exhibido una y otra vez frente a distintos actores para lograr fortaleza y visibilidad, generar nuevos apoyos, y garantizar su protección frente a eventuales abusos estatales. Esta constante manipulación de las fronteras del "nosotros" de la aldea demuestra un refinamiento del saber sobre el funcionamiento del Estado.

\section{El parque de los "trolos"}

El primer día que visité la aldea junto a una colega, los encargados de seguridad de Ciudad Universitaria nos advirtieron entre risas, al vernos enfilar hacia el sendero: "Este es el Parque de la
Memoria, y este es el parque de los 'trolos' ${ }^{10}$. Y ustedes van a ser las desaparecidas". El chiste remite al daño que ellos (los "trolos") podrían infligirnos a nosotras (mujeres jóvenes), y remite también a un macabro juego de palabras con la proximidad física del Parque de la Memoria en construcción, al que comúnmente se alude como "el parque de los desaparecidos". Sabemos de lo revelador que resulta analizar las creencias en materia de contaminación en relación con las ideologías sexuales (MOORE 1996, p.30). Aquí notamos cierta afinidad con aquellos estudios de simbolismo de género que muestran a la mujer como agente contaminante y peligrosa: en este caso, los "trolos" serían aquellos agentes tan contaminantes y peligrosos como para provocar nuestra desaparición. De la supuesta impureza de su condición sexual se deduce una moralidad distanciada, o no moral: ellos pueden provocarnos un daño ominoso. Su posibilidad de dañar a otro sería ontológica, inherente a su "naturaleza" que es considerada, al mismo tiempo, como "antinatural". La anécdota sirve para mostrar la "cadena lógica de significados" (HALL, 1985, p. 112-113) que se construye, desde el sentido común, alrededor de los habitantes de la Aldea Gay: ser pobre, cartonero, gay o travesti, aunque sin el plusvalor cultural de la Comunidad Homosexual Argentina o un travesti legitimado como la estrella televisiva Florencia de la $\mathrm{V}^{11}$. Un abogado de un organismo de derechos humanos, que trabajó activamente con la población gay, me describió la fundación de la aldea como una "reacción de ellos" frente a las intimidantes declaraciones del entonces influyente monseñor Quarracino: "No había nadie. Era un terreno recuperado [...] Eran pobres, putos y ya eran cartoneros en esa época."

Este comentario sintetiza la concepción predominante acerca de los primeros pobladores de la aldea: se trata de individuos considerados "contra natura" 12 , usurpando el imperio de lo natural. Si una unión "contra natura" justifica per se la condena moral, de ella se infieren una serie de conductas y comportamientos culturales. Los habitantes gay de la aldea se quejaban de ser "basureados por Desarrollo Social", ya que las trabajadoras sociales no admitían su condición de pareja:

Pareja son hombre y mujer para mí, nos decía. Ustedes para mí son dos solteros (La Pedro).

Una discriminación similar fue denunciada a propósito del desalojo del '98, en el cual los funcionarios planificaban otorgar chapa y material para construir una vivienda solo a las "familias tradicionales" y "para el resto, los caños". La expresión pertenece a un funcionario de la Subsecretaría de Derechos Humanos, que luego tuvo que ser subsanada por el Secretario de Promoción Social, que aclaró que su postura era "absolutamente antidiscriminatoria" y que se 
otorgarían materiales tanto a las "parejas ortodoxas como no". En la práctica solo hubo, como vimos, un desalojo sumamente violento.

\section{Vecinos Unidos y la monumentalización de la naturaleza}

A fines de 2002, los habitantes de la aldea organizan la cooperativa de vivienda Vecinos Unidos, con la ayuda de ONGs, organismos de derechos humanos y profesores universitarios. Luego de innumerables conflictos internos, se consolida el proyecto de construir un barrio en unos terrenos del Gran Buenos Aires: el Gobierno aporta terreno y materiales, y los vecinos su mano de obra. Simultáneamente a la conformación de la cooperativa, siguen prosperando los dos proyectos a desarrollarse en aquellos terrenos: el Parque de la Memoria y el Parque Natural. Se trata de dos proyectos diferenciados, uno contiguo al otro. El Parque de la Memoria fue motorizado por los organismos de derechos humanos, y su objetivo consiste en rendir homenaje a las víctimas del Terrorismo de Estado de la última dictadura militar. El Parque Natural, contiguo al Parque de la Memoria, es gestionado por el poder local como un paseo novedoso que busca revalorizar el frente costero de la Ciudad. Una vez que toma forma el proyecto de "trasladarlos"13, se suceden los censos sobre su población. Los habitantes de la aldea objetan la arbitrariedad de los censos, que dejan a muchos "antiguos" fuera de la operatoria:

Por ser gay es una discriminación. Por ser excluidos. Hay 14 fuera del censo, sin DNI por ser chicos de la calle, pero todos son argentinos [...] Ellos tienen derechos como yo, como cualquiera... (La Pedro).

Por un lado, la consolidación de la cooperativa disuelve parte de la amenaza que estos habitantes representan para el afuera. Al mismo tiempo, el Estado se vale de este nuevo actor colectivo, la cooperativa, para legitimar la política de expulsión en torno al supuesto consenso alcanzado.

\section{El doble discurso del Estado}

En mayo de 2006 se incendia una casilla en Aldea Gay. Mueren tres personas, entre ellas un bebé. La flamante Ministra de Derechos Humanos y Sociales aclara entonces que las casi 90 familias del asentamiento están organizadas, y serán trasladadas en breve a unas "casitas" que estaban por construirse en Villa Rosa, partido de Pilar. No obstante las declaraciones públicas, el proyecto de la cooperativa es desestimado abruptamente por el poder local por motivos contradictorios y difíciles de elucidar. Los trabajadores sociales intervinientes responsabilizan a los habitantes de que el proyecto se venga abajo, ya sea por su supuesta falta de educación o por no ser "familias", aunque diluido en un tono paternalista:

Fue muy complicado hacer ingresar a hombres solos. [...] Son así de pintorescos, me matan [...] Aunque para ser cartoneros se hacen entender bien [...] Sacarlos de este lugar es lo mínimo que podemos hacer (Trabajadora social del Gobierno de la Ciudad).

Considerados ciudadanos de segunda, sus derechos son proporcionales, pues, a su "inacabada humanidad". Menos eufemísticos, los habitantes gay traducen el conflicto en sus términos:

Los solteros superaban a todas las familias y decidieron que no. Lamentablemente la tiraron abajo porque somos cartoneros, trabajadores independientes (Julio).

Para entender el fracaso del proyecto cooperativo debemos volver sobre un nuevo aspecto de la valoración simbólica atribuida a los gays/travestis, por contraposición a las familias de la aldea. En la coyuntura de la expulsión de la villa, ser gay equivalía a una condición anómala de soltero y no ser (verdadera) familia ${ }^{14}$. Los gays fueron pensados en términos negativos, o bien como una categoría residual y ex-céntrica. La idea de familia que se toma como referente para remarcar la anomalía de los gayssolteros no describe una materialidad previa, sino que "regula y vuelve inteligible la materialidad de los cuerpos" (BUTLER, 1992) que caen dentro o fuera de los significados previstos.

Off the record, un trabajador social del gobierno luego destituido admitió que la ley impuso la obra del parque costero, y que el magro subsidio monetario que finalmente se les otorgó para expulsarlos fue una forma de chantaje:

La orden [de que "se caiga" la cooperativa] fue de arriba para abajo [...] Hay un ensalzamiento de lo popular vaciándolo... Se trabaja mucho desde lo individual o familiar. Todo lo que es colectivo, ellos [el Gobierno de la Ciudad] no quieren tomarlo [...] Y tampoco se quiere sentar antecedentes de procesos autogestivos de vivienda en zona norte.

Desde la perspectiva oficial, la operatoria fue un éxito. El poder local validó el desalojo hacia ninguna parte arguyendo que se buscó una solución habitacional acorde a "las necesidades de la cooperativa", aunque sin aclarar que la solución habitacional oficial fue precisamente la que desmembró el proyecto cooperativo de vivienda. 
En mayo de 2006 se firma el convenio entre los vecinos y el Gobierno de la Ciudad mediante el cual se pacta la entrega de subsidios monetarios para que cada familia "elija libremente" dónde comprar su casa. Al igual que en los demás desalojos de la ciudad, la suma de dinero que obtiene cada familia resulta insuficiente para procurarse un techo. Hay vecinos que, no obstante, reciben con beneplácito la llegada del subsidio, pues no creen que exista alternativa, y se sienten atemorizados por el posible uso de la violencia.

En los momentos más dramáticos de su vida, afirman los habitantes gays/travestis, no recibieron sino un trato inhumano por parte del Estado. El ex Jefe de Gobierno De la Rúa ${ }^{15}$, según sus expresiones, los expulsó en el '98 como bichos, o entre el barro, como animales. Una trabajadora social recurrió a una de estas metáforas zoológicas para referirse a su primera impresión de la aldea: "Cuando vi como vivían, como ratas, me quería morir...". Existe un tratamiento diferencial de los sectores populares según cómo es percibido y apreciado su capital económico, cultural y social. Así como se intenta favorecer a los pobres más cercanos a la clase media - por su trayectoria, vocabulario, expectativas o modales que resultan "familiares" -, los más marginales no resultan interlocutores válidos. Un abogado de un organismo de derechos humanos pugnó por conseguir que una familia de la aldea sea incluida en un plan de viviendas del gobierno - porque estaba encariñado con ellos y los consideraba "pobres meritorios" (BOURDIEU, 1999, p. 163) -, pero tomó distancia de la negativa oficial de apoyar la cooperativa ya que, según sus palabras, los gays son "quedados, poco luchadores", y "cada uno obtiene según lo que le corresponde": "Los gays es un puterío, se pelean entre ellos... Están re victimizados. ¿Qué planteos pueden hacer ellos al Gobierno?”

Este profesional estaba al tanto de los continuos abusos que los habitantes gays o travestis habían sufrido por parte de la policía, de los cuales no habían presentado denuncias. ¿De esto deberíamos inferir que, si las víctimas "sobreactúan" su condición es porque existe un goce no admitido en el hecho de haber padecido violencia? ¿O refiere a que, al haber interiorizado en exceso su estatus de víctimas tendrán obturados toda agencia, o derecho a réplica, frente a nuevos atropellos? La condición de "victimizados" de este sector de población, ¿atenúa retroactivamente la violencia ejercida sobre ellos, borra la responsabilidad de los culpables, o bien habilita un continuo ejercicio de la violencia ${ }^{16}$ ?

Que el discurso oculto de estos actores clave emergiera a la luz frente a mí resultó comprensible por lazos sociales previos conmigo: con uno de ellos tenemos la misma edad, y nos habíamos conocido tiempo antes en el cumpleaños de un amigo en común. Él no hubiese confiado su verdadero sentir a una antropóloga a quien no hubiese considerado un igual. Confesiones de esta intimidad surgieron también con una funcionaria municipal: en este caso, el puente entre nosotras fue nuestra mutua condición de trabajadoras sociales, mi carrera de origen. Ambas circunstancias me permitieron ser testigo privilegiada de la "dramática desigualdad entre el discurso público y el oculto" (SCOTT, 2004, p. 28). En la mayoría de las entrevistas con funcionarios o empleados municipales - ya fuesen en su despacho o compartiendo un viaje en colectivo - no pude cruzar ese asombroso umbral que pudiera transportarme de las respuestas estandarizadas a los verdaderos motivos, más complejos, de las acciones públicas decididas en la intimidad.

Las trabajadoras sociales que habían sido alumnas mías en la universidad fueron las interlocutoras más reticentes. El mutuo conocimiento jugó en contra en el trabajo de campo: ellas estaban comprometidas en el proceso de desalojo de la villa, e intuían mi desacuerdo moral con su modus operandi. El espeso silencio reinante en las entrevistas resultaba un rico analizador del vínculo, y de la vigilancia moral que ellas suponían que yo ejercía sobre ellas, bajo los pliegues de mi tono ecuánimemente afable. Incluso hubo situaciones en las que mi entrevistada, sintiéndose juzgada por mi silencio, irrumpía en explicaciones de índole personal para justificar su participación en la operatoria de expulsión, aclarando que el trabajo no le agradaba pero que no podía conseguir el traslado a otra dependencia, o que se veía forzada a trabajar allí para pagar la hipoteca de su casa. La controvertida actuación de las trabajadoras sociales del poder local en estas operatorias de expulsión de sectores populares fue abordada con detalle en otro trabajo (CARMAN, 2008), al cual remito al lector.

La mudanza no deseada de la "aldeanos" alteró, como ya había sucedido con el desalojo anterior, todo el circuito de la supervivencia, y supuso también la interrupción de los tratamientos contra el HIV de las personas infectadas. No tengo oportunidad de desplegar aquí in extenso las múltiples y complejas contestaciones de los habitantes de la Aldea Gay frente a la coyuntura de la expulsión ${ }^{17}$. Quiero al menos señalar la recurrente exaltación y apelación al cuidado del entorno natural que fue esgrimido por los habitantes junto a la celebración de su condición sexual pues se trató, para ellos, de dos experiencias inextricablemente unidas. En tales testimonios prevaleció no un tono de denuncia, sino de humor o sarcasmo.

V: [...] Nosotros de última cuidamos la naturaleza más que ellos [el Gobierno]. Más que la UBA [la Universidad de Buenos Aires].

A: (lo interrumpe con gesto de desaprobación) Se vienen a llevar las palmeras...

$\mathrm{V}$ : Yo no acepto que nadie venga a cazar aquí.

A: [Los responsables de la obra del Parque Natu- 
ral] Tiraron muchos árboles. Esta zona tenía todo árboles...

V: ¡Decí que los parábamos, porque sino los tiraban encima de nosotros! (Vicente y Alfredo).

Lo verde es hermoso... [...] Yo si tengo que morir [está preocupado pues no se anima a hacerse los análisis de HIV] no me arrepiento de haber sido puto. Al haber sido aventurero he acelerado muchas etapas de un ciudadano común pero bué... fue lindo. Me gustaría morir así acá (Gustavo).

G: En la balanza, hemos sido felices...

L P: Yo me sentí en el mundo en que quería estar. Sobrevivir en el lugar, en contacto directo con la naturaleza. [...][Ahora] nos cortaron la pesca. Bajo todo punto de vista... (risas) Yo la aldea la llevo en el alma. [...] Voy a levantar otra vez mariquitas de la calle para refundar la aldea (Gustavo y La Pedro).

Comparece en estos testimonios una singular agudeza para dar cuenta de su posición en el mundo, y de las distancias que los separan de los "ciudadanos cocomunes ${ }^{18}$ ". Se trata de argumentos que ellos no esgrimen frente a los funcionarios o empleados públicos - con quienes se muestran conciliadores en público - sino frente a interlocutores externos no comprometidos con su expulsión, ambigua categoría que me incluye. La prudencia y la afabilidad constituyeron el repertorio central de los habitantes de la aldea en encuentros con los trabajadores sociales a cargo de su expulsión: si bien deslizaban chistes o

\section{El "parque de los trolos" no} conformó, como vimos, un estereotipo de lo gay aislado, sino que entrecruzó estigmas de género y clase social. Ser gay puede resultar incluso más estigmatizante que ser pobre.

\section{Epílogo: ¿La clase social entre paréntesis?}

El "parque de los trolos" no conformó, como vimos, un estereotipo de lo gay aislado, sino que entrecruzó estigmas de género y clase social. Ser gay puede resultar incluso más estigmatizante que ser pobre. En esta coyuntura, se trata de una marca cuyo principal efecto es agravar la exclusión de quienes la portan. Los sectores persuadidos de la necesidad de "trasladar" a los intrusos enfatizan la pertenencia de clase de estos últimos, ya sea invocando argumentos altruistas - sus condiciones infrahumanas de vida - o abiertamente deshumanizantes.

Simétricamente, los sectores interpelados tienden a soslayar la adscripción de clase cuando esta es la principal categoría que organiza la acusación ajena. En el caso de la aldea, la pertenencia a la clase social se soslaya al invocar el armado de una comunidad gay pionera. Los "aldeanos" recurren a aquellas ONGs para cuya sensibilidad resulta inadmisible que una “comunidad gay" viva sin luz ni agua. Ellos saben, como ironizan Fonseca e Cardarello (2005), de las dificultades que atraviesan los que no han sido rebautizados bajo una categoría políticamente correcta. Resulta más fructífero negociar su inclusión social desde esa individualidad parcialmente reconocida (ser gay) que desde el hecho de ser cartonero o, peor aún, pobre a secas.

Estos desplazamientos, diría Bourdieu (1990, p. 285292), maximizan el beneficio de esa denominación; y acaso el autor esté en lo cierto cuando sugiere que los trabajos de producción simbólica se potencian bajo situacio- quejas, no había una oposición explícita a sus planteamientos. La aceptación del patrón paternalista de comunicación ofrecido por los agentes estatales se transformaba, una vez que estos últimos se retiraban de escena, en un sofisticado arsenal de comentarios cínicos. ¿Es que los subordinados, como supone Scott (2004, p.33-35), actúan una máscara en presencia del poder, y representan convincentemente la humildad y el respeto? Me inclino a pensar, en cambio, que la contestación al dominante se ritualiza en ciertos escenarios colectivos, y sus posturas de rechazo asumen formas indirectas o altamente estetizadas. Mi intención no consiste en suponer falsedad en los vínculos desiguales y autenticidad con los propios, sino en procurar comprender la complejidad de tales vínculos, máxime si tenemos en cuenta del constante - y justificado - temor de estos y otros habitantes de villas en el posible uso de violencia en la expulsión. nes de crisis. Bourdieu va más lejos, y afirma que los agentes difícilmente sean capaces de oponer mundos posibles y diferentes al mundo social cuando las condiciones de existencia son más penosas. Por el contrario, creo que el juego de lo simbólico no disminuye en la medida en que el "torno" de la necesidad aprieta, según la gráfica expresión de Grignon y Passeron (1991); y la imprevisible ductilidad de los discursos y prácticas populares así lo demuestran.

No obstante, los "aldeanos" sí se definen como pobres cuando objetan la incomprensión de sus padecimientos por parte de la sociedad, o denuncian su exclusión de ciertas políticas públicas. Y también refuerzan su pertenencia de clase cuando acentúan la experiencia solidaria de haber rescatado "chicos de la calle". El argumento filantrópico sirve aquí para desmarcarse de las conductas impropias de ( $\mathrm{su}$ ) clase que les son imputadas: usurpar, delinquir. 
La apelación a la clase social por parte de los “intrusos" es intermitente o bien, como está de moda decir estos días, "estratégica ${ }^{19 "}$ ". Se trata de restauraciones semánticas ajustadas a los requerimientos de la ocasión: de villeros a guardianes de la naturaleza, de gays a chicos de la calle, o bien de chicos de la calle a pioneros de una comunidad. Elénfasis en la cuestión de clase queda así, temporariamente, desplazado. Ellos pueden regresar sin grandes pérdidas, si las circunstancias así lo requieren, a la unidad mínima de los habitantes "nativos", imaginada como duradera o estable.

No hay una correspondencia necesaria, en fin, entre las condiciones de una relación social o práctica, y los distintos modos en que estas pueden ser representadas (HALL, 1985, p.104). Esto no implica desdeñar el anclaje de esas identidades en una determinada "alteridad histórica" (SEGATO, 1998), o abandonar la inscripción de sus discursos y prácticas en mapas e historias específicos (GILROV, 1993 apud CLIFFORD, 1991). Por el contrario, solo quiero advertir sobre los peligros de atribuir a priori a un grupo social - por lo general recortado en términos de clase social - cualidades idénticas.

En el caso de los pobladores de la aldea, sus prácticas de reivindicación de una comunidad gay pionera nos llevan a pensar a las identidades de los grupos sociales como no fijadas de antemano por la pertenencia a una clase social. Si el Estado u otros actores enfatizan su condición de indigentes, ellos acentúan o desplazan esa pertenencia de clase conforme a la coyuntura. Aquello que era recortado como el más abominable estigma posible - su condición de gays, travestis y cartoneros los proveyó a ellos, paradójicamente, de un lenguaje común que resultó provechoso para gestionar plásticamente su pertenencia grupal.

\section{Referencias}

BUTLER, J. Fundamentos contingentes: el feminismo y la cuestión del "postmodernismo". Traducción de Moisés Silva. In: .; SCOTT, J. W. (Ed.). Feminists Theorize the Political. London: Routledge,1992. p. 8-41.

..; SPIVAK, G. ¿Quién le canta al Estado-Nación? Lenguaje, política, pertenencia. Buenos Aires: Editorial Paidós, 2009.

BOURDIEU, P. Sociología y cultura. México D.F.: Editorial Grijalbo, 1990.

La dominación masculina. La ventana, Revista de Estudios de Género de la Universidad de Guadalajara, n. 3, México, 1996.

La miseria del mundo. Buenos Aires: Fondo de Cultura Económica, 1999.
CARMAN, M. Políticas del desamparo: superfluidad y represión. Revista Ciudades. Red Nacional de Investigación Urbana, Puebla, México, n. 78, p. 21-27, abr.jun.2008.

.Lo puro y lo impuro. Dimensiones de la segregación socio-espacial en Buenos Aires. En: CONGRESS OF THE LATIN AMERICAN STUDIES ASSOCIATION. Session: Desigualdad y Sociabilidad Urbanas. Rio de Janeiro, Brasil, 2009a. (inédito).

. Las trampas de la naturaleza. Medio ambiente y segregación en Buenos Aires. 2009b. (inédito).

CLIFFORD, J. Travelling Cultures. In: GROSSBERG, N.; TREICHLER (Ed.). Cultural Studies. New York: Routledge, 1991.p. 96-116.

DOUGLAS, M. Pureza y peligro. Un análisis de los conceptos de contaminación y tabú. Madrid: Siglo Veintiuno Editores, 1991.

ELIADE, M. Mito y realidad. Barcelona: Editorial Labor, 1992.

FONSECA, C.; CARDARELLO, A. Derechos de los más y menos humanos. In: TISCORNIA, S.; PITA, M. V. (Ed.). Derechos humanos, tribunales y policía en Argentina y Brasil. Buenos Aires: Editorial Antropofagia, 2005. p. 9-41.

FOUCAULT, M. Historia de la sexualidad 2. El uso de los placeres. Madrid: Siglo XXI Editores, 2008.

GARCIA GUAL, C. Introducción a la mitología griega. Madrid: Alianza Editorial, 1995.

GIDDENS, A. La constitución de la sociedad. Buenos Aires: Ediciones Amorrortu, 1995.

GIROLA, M. F. Modernidad histórica, modernidad reciente. Procesos urbanos en la Área Metropolitana de Buenos Aires: los casos del Conjunto Soldati y Nordelta. Tesis (doctorado, Facultad de Filosofía y Letras) Universidad de Buenos Aires. 2008.

GRIGNON, C.; PASSERON, J.C. Lo culto y lo popular. Miserabilismo y populismo en sociología y en literatura. Buenos Aires: Ediciones Nueva Visión, 1991.

HALL, S. Signification, Representation, Ideology: Althusser and the Post-Structuralist Debates. Critical Studies in Mass Comunication, v. 2, n. 2, p. 91-114, 1985.

MOORE, H. Antropología y feminismo. Valencia: Ediciones Cátedra, 1996. 
RIVIÈRE, C. Culture inavouée dans la nature, nature soumise dans la culture. Horizontes Antropológicos, Porto Alegre, año 7, n.16, p. 85-112, 2001.

SEGATO, R. The Color-Blind Subject of Myth, or Where to Find Africa in the Nation. Annual Review of Antrhopology, Palo Alto, CA, n. 27, p. 129-151, 1998.

SCOTT, J. Los dominados y el arte de la resistencia. México D.F.: Ediciones Era, 2004.

\section{Notas}

1 Distinto es el caso de los sectores populares que se denominan colectivamente como villeros, hoteleros o piqueteros en la disputa por sus derechos; aunque esta distinción debería cotejarse en un trabajo de campo más exhaustivo.

2 Forma despectiva de referir a los homosexuales varones.

3 Sería interesante contrastar, en un futuro trabajo, de qué modo los residentes de urbanizaciones cerradas también aluden a relatos de tiempos míticos y a su confianza en lazos comunitarios novedosos para legitimarse (GIROLA, 2008). Las disquisiciones sobre la fundación mítica de la aldea son retomadas del magnífico trabajo de MirceaEliade (1992).

4 Coloquialmente, tener relaciones sexuales.

5 No viene de más recordar que, en la tradición filosófica griega, el placer sexual era considerado ontológicamente inferior por depender del cuerpo y sus necesidades, y por ser común a los animales y los hombres; no constituyendo, así, una cualidad específica de estos últimos (FOUCAULT, 2008, p. 48). La digresión resulta pertinente para trazar analogías con otros sectores populares que también son homologados a un estatus animal.

6 Coloquialmente, un militar o, por extensión, un policía.

7 Comoseñalan Butlery Spivak (2009,p. 53-71), el poderestatal instrumentaliza el criterio de ciudadanía para producir y fijar una población en su desposesión. Las autoras abordan de qué modouna "humanidad espectra"'lque no pasa las pruebas de inteligibilidad social requeridas para ser mínimamente reconocida es "producida" como sin-estado, al mismo tiempo que despojada de formas jurídicas de pertenencia.

8 Respecto a los dos grandes temas míticos - la cosmogonía y la escatología(GARCÍA GUAL, 1995, p. 20-26).

9 La recapitulación sobre esta confianza cultural adquirida no busca negar un hecho evidente: que las condiciones materiales de existencia también inciden en la disputa por la permanencia. Sabemos que la precariedad estructural de la aldea no obstaculizó la construcción de un fuerte sentido de pertenencia por un sinnúmero de razones: la identidad gay, la relación con la naturaleza y el río, los sufrimientos compartidos. Hacia el mundo público, no obstante, esas condiciones precarias fueron percibidas como un signo de debilidad en la negociación. Los habitantes de la aldea creían tener derechos restringidos sobre el lugar por el estado de sus ranchos, sensación que se vio agravada posteriormente a partir del episodio del incendio y la operatoria de expulsión.

10 En Argentina, "trolo" - al igual que puto - equivale a un modo despectivo de nombrar a los homosexuales.

11 Como señala Moore (1996, p. 33,51) respecto de las imágenes de la mujer, las imágenes de los hombres gay y de los travestis difieren según los sectores de la sociedad y las esferas del mundo cultural. El valor de analizar al hombre y la mujercomo categorías o construcciones simbólicas reside en identificar las expectativas y valores que una cultura concreta asocia al hecho de ser varón o hembra. Dichas imágenes tienen, además, una relativa autonomía simbólica: "no son plenamente independientes de las relaciones económicas de producción ni derivan directamente de ellas."

12 Platón opone la relación "conforme a natura" que une al hombre y la mujer y la relación "contra natura" de varón y varón o hembra con hembra, señaladas como prácticas que contravienen la naturaleza, el principio de la procreación, y que se asocian a una intemperancia del placer (FOUCAULT, 2008, p. 43-44). La expresión “contra natura", como señala Rivière (2001,p. 21) articula en forma compleja lo moral y lo biológico, y es empleada como juicio de valor perentorio de aquello que supuestamente atenta contra el orden cultural, vivido como el "orden natural de las cosas". Aquí el uso de la palabra naturaleza refiere exclusivamente a la naturaleza humana y al modo en que esta es concebida.

13 En su intento de distanciarse de la violenta expulsión del '98, una trabajadora social del poder local corregía a los pobladores de la aldea en las reuniones aclarándoles que no se trataba de un desalojo, sino de un traslado.

14 Cuando algo está firmemente clasificado como anómalo, señala Douglas (1991), los límites de la serie de la que no forman parte se clarifican.

15 La Comunidad Homosexual Argentina inmortalizó durante años a De la Rúa en el mural "Imágenes y palabras de la discriminación" expuesto en la Semana y Marcha del Orgullo Lésbico Gay Travesti Transexual Bisexual, por ser uno de los principales políticos que hizo pública su actitud discriminatoria.

16 Me resultó inspirador el trabajo de Butler (1992) sobre la violación de una mujer, en la cual la figura de su sexo es asociada - por estar fuera del espacio de la domesticidad - a una "natural proclividad a la expropiación". Bajo esta 
representación, los mismos términos por los cuales se explica la violación "ponen en acción" la violación, y conceden que la violación ya estaba en proceso antes de que tome la forma empírica de un acto criminal.

17 Al respecto, cfr. Carman (2009a; 2009b).

18 Retomando a Van Stolk y Wouters, Bourdieu comenta la lucidez especial de los dominados que "ven más de lo que son vistos", y retoma el caso de los homosexuales abordado por tales autores: "[...] los homosexuales, habiendo sido criados como heterosexuales, han interiorizado el punto de vista dominante, por lo que pueden adoptar ese punto de vista sobre ellos mismos, [...] y pueden comprender mejor el punto de vista de los dominantes de lo que éstos alcanzan a entender el suyo“"(BOURDIEU 1996, p. 7). Para apreciar el valor de modalidades expresivas como el humor oel sarcasmo en tanto "penetración inteligente" frente a ambientes sociales opresivos, me resultó inspirador el trabajo de Willis, comentado por Giddens (1995, p. 314-318).

19 Dicha astucia de la sustitución no es privativa de una clase social en particular. Otro tanto podría señalarse respecto a la experiencia de asambleístas que recuperaron inmuebles abandonados tras la crisis de 2001, y enfrentaron las acusaciones de usurpación reivindicando el armado de proyectos culturales de mayor alcance. Por su parte, los moradores de los barrios cerrados hacen hincapié en sus actividades benéficas para distanciarse de la apatía social atribuida a su estilo de vida. Ellos quizás viven, com o suele decirse, "en una burbuja"; peroesono les impide emprender la solidaridad hacia los indigentes. La clase social de pertenencia se pone en suspenso - si cabe la metáfora - para pasar a nombrar a aquellos de menor rango favorecidos por sus prácticas desinteresadas. Lo curioso es que, como señalaba Boothafines del siglo 19, pareciera haberunalíneaque demarca los límites entre los pobres a los cuales se ayuda (los "pobres respetables") y a los que se teme (los "pobres no respetables"). Pero la puesta entre paréntesis de la clase es, también en este caso, coyuntural. Si las conductas tan temidas provienen de la endogamia -como el vandalismo de algún hijo adolescente-, la pertenencia de clase será invocada pertinazmente para resolver los conflictos puertas adentro del barrio cerrado, hasta transformar el delito en mera travesura doméstica.

\section{María Carman}

mariacarman@sinectis.com.ar

Dra. en Antropología Social pela Universidad de Buenos Aires (UBA)

Docente de la Uba e Investigadora del Consejo Nacional de Investigaciones Científicas y Técnicas (Conicet)

\section{UBA - Facultad de Ciencias Sociales}

Santiago del Estero, 1067

Buenos Aires - Argentina 